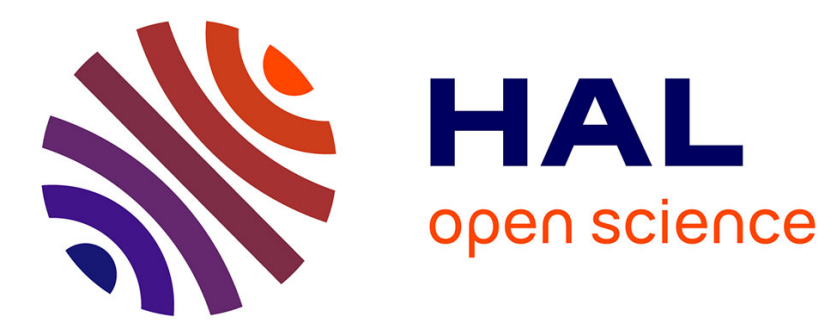

\title{
Geometrical and mechanical draping of composite fabric
} Abdelhakim Cherouat, Houman Borouchaki, Jean-Louis Billoët

\section{To cite this version:}

Abdelhakim Cherouat, Houman Borouchaki, Jean-Louis Billoët. Geometrical and mechanical draping of composite fabric. Revue Européenne des Éléments Finis, 2005, 14 (6-7), pp.693-707. 10.3166/reef.14.693-707 . hal-00020293

\section{HAL Id: hal-00020293 https://hal.science/hal-00020293}

Submitted on 27 Mar 2018

HAL is a multi-disciplinary open access archive for the deposit and dissemination of scientific research documents, whether they are published or not. The documents may come from teaching and research institutions in France or abroad, or from public or private research centers.
L'archive ouverte pluridisciplinaire HAL, est destinée au dépôt et à la diffusion de documents scientifiques de niveau recherche, publiés ou non, émanant des établissements d'enseignement et de recherche français ou étrangers, des laboratoires publics ou privés.

\section{(c)(1)}

Distributed under a Creative Commons Attribution| 4.0 International License 


\section{Geometrical and mechanical draping of composite fabric}

\section{Abdelhakim Cherouat* — Houman Borouchaki* Jean-Louis Billoët**}

* LASMIS - CNRS FRE 2719, Université de Technologie de Troyes BP 2060, F-10010 Troyes

abdelhakim.cherouat, houman.borouchaki@utt.fr

** LMSP - CNRS UMR 8106, ENSAM-ESEM et Ecole polytechnique de l'Université d'Orléans, 151 Bd de l'hôpital, F-75013 Paris

jean-louis.billoet@univ-orleans.fr

ABSTRACT. This paper presents an optimization based method for simulation of forming processes of woven fabric reinforced composites. Two approaches are proposed for the simulation of the forming of woven fabric: geometrical and mechanical. The geometrical approach is based on a fishnet model. It is well adapted to pre-dimensioning fabrics and to give a suitable quantification of the resulting flat patterns. The mechanical approach is based on a mesostructural model. It allows us to take into account the mechanical properties of prepreg fabric and the various dominating mode of deformation of woven fabrics during the forming process. Some numerical simulations of forming process are proposed and compared with the experimental results in order to demonstrate the efficiency of our approaches.

RÉSUMÉ. Ce papier traite le problème d'optimisation de la mise en forme des tissus composites pré-imprégnés. Deux approches complémentaires sont proposées pour modéliser le drapage de ces matériaux: une approche géométrique et une approche mécanique. La première est basée sur le modèle du filet et s'inscrit dans une démarche de prédimensionnement, la seconde est basée sur une approche mesostructurale et s'inscrit dans une perspective d'optimisation de la conception et la fabrication de pièces composites.

KEYWORDS: Pre-preg woven fabric, fibres and resin, forming process, MOSAIC algorithm, meso-structural formulation, truss and membrane finite elements.

MOTS-CLÉS : pré-imprégnés, fibres et résine, mise en forme, algorithme MOSAIC, formulation mésostructurale, éléments finis de barre et de membrane. 


\section{Introduction}

Composite materials with glass, carbon or aramid fibres and polymeric matrices are known to have high specific strengths and stiffness and, in combination with automatic manufacturing processes, make it possible to fabricate composite structures with high level of weight and cost efficiency. As known, the substitution of metal alloys by composite materials, in general, reduces structures mass by 20 $30 \%$. This increasing is due also to the numerous variety of semi-products (roving, fabrics, knitted fabrics, braids pre-impregnated or not) permitting the elaboration of structures. Fabrication processes, also, have undergone substantial evolution in recent years. Although the traditional hand lay-up process will remain the process of choice for some applications, new developments in resin transfer moulding, sheet moulding compound, low temperature curing prepregs and low pressure moulding compounds are reached new heights of sophistication, and are now being exploited in high technology areas such as aerospace industry (Binétruy, 2004).

The choice of manufacturing process depends on the type of matrix and fibres, the temperature required to form the part and the cost effectiveness of the process. Often, the manufacturing process is the initial consideration in the design of composite parts. Each manufacturing process imposes particular limitations on the structural design. It is necessary to develop specific algorithms taking into account not only the appropriated mechanics of the semi-products but also the associated process. Different levels of modelling intervene in the design process: architecture design level, pre-dimensioning level, mechanical level by computational software and optimisation level (Kawabata et al., 1973, Cherouat et al., 1995, Lim et al., 1999, Rozant et al., 2000, Boisse, 2004) and (Liu et al., 2005).

Most of these levels are integrated and take into account specificities of manufacturing processes. In the case of prepreg composite fabrics, these materials give flexibility in the design manufacture and play an important role in increasing the use of advanced composites. But for the manufacturing of non-developable preimpregnated fabric composite parts, a new problem intervenes in the design chain resulting of the number of parameters influencing the global behaviour of composite forming process. The ability to define, in advance, the ply shapes and material orientation allowed the engineers to optimise the composite structural properties of the composite products for maximum strength, maximum material utilisation and maximum lay-up efficiency.

Hand lay-up is the most common method of producing thin composite parts (Rozant et al., 2000) and (Binétruy, 2004). The primary methods of automation in hand lay-up relate to computer software. Software is used to generate flat patterns from the layer surface and the ply boundary and to find the most efficient nest of cut plies to minimize the scrap. The formulation of the more efficient numerical models for the simulation of the forming composite processes must delays in manufacturing of complex parts and an optimisation of costs in an integrated design approach. The 
composite manufacturing process involves large displacements and rotations and large shears of weft and warp fibres, which can have a significant effect on the processing and structural properties of the finished product. We propose two different numerical approaches to simulate the deformation of prepreg woven fabrics by shaping process: geometrical approach and mechanical approach (Van Der Ween, 1999, Cherouat et al., 2001, Borouchaki et al., 2003, Boisse, 2004) and Harrison et al., 2004). The numerical simulation is an efficient means of evaluating factors related to manufacturing processes and an efficient help to design preforming sequence for the manufacturing of fabric reinforced composites. It is possible to detect main problem occurring during the shaping deformation and to obtain good quantitative information on the forming process.

The geometrical approach is well adapted to pre-dimensioning level. It is based on geometrical aspects of the warping. Our method is based on a modified "MOSAIC" algorithm, which is suitable to generate a regular quad mesh representing the lay-up of the curved surfaces (giving the exact fibre orientations). The method is implemented in the GeomDrap software (Borouchaki et al., 1999) which is now integrated in the ESI-Pam software. This software provides a fibre quality chart (showing the fibre distortions, the rate of falling and the rate of draped surface) to predict difficult impregnated regions. It can be used to optimise the draping process (with respect to the above quality measure) by improving the lay-up directions or the marker data location. The lay-up of complex curved surfaces can be made in a few seconds.

Our mechanical approach is based on a mesostructural level. It permits to take into account the various dominating mechanics in the physics of the mechanical transformation of prepreg fabrics during the shaping process, namely large angular variations of yarns, viscoelasticity of resin and evolution of possible damages in yarns. The different advantages of this modelling is first to give the ability to obtain a very good material orientation of yarns and consequently to introduce good data in the pre-processing of the calculation of the final piece after polymerisation, secondly to give the mechanical limits of the fabric during the forming process and finally to limit the falls of the fabric by on better definition of the flat form (Cherouat et al., 2001). Different numerical simulations and experiments of shaping process have been carried out in order to validate the proposed computational formulation. The various forming parameters examined have included the initial shape of fabric, the fibre orientations and the viscosity of resin.

\section{Discrete geometrical approach}

First, we recall the mathematical formulation of the geometrical draping and then we propose an algorithm to solve the draping problem. Let denote by $\Sigma$ the surface to drape. We assume that a geometrical mesh $T_{\Sigma}$ of surface $T_{\Sigma}$ is known. Let $F$ be the woven fabric modelled by two families of mutually orthogonal and inextensible 
fibre described by the coordinates $x=(\xi, \eta)$. These families constitute regular quad mesh $T_{F}$ of the fabric $F$ (see Figure 1). The problem of draping of woven fabric $F$ onto the surface $\Sigma$ consists of associating each node of $\mathrm{T}_{\mathrm{F}}$ with a point of the surface mesh $\mathrm{T}_{\Sigma}$ such that the lengths of the edge of the corresponding mesh $\alpha$ on the surface are preserved. This problem presents an infinity of solutions depending on the first node of $\mathrm{T}_{\mathrm{F}}^{\Sigma}$ (called the point of impact) associated with a node of $\mathrm{T}_{\mathrm{F}}$ and on the direction of the fabric co-ordinate axes at this node. Thus, to ensure a unique solution, we suppose that the points of impact on the surface as well as the fabric orientation at this point are known. The draping process is given by the following scheme (Borouchaki et al., 2003):

1. associate a node $x_{0}=\left(\xi_{0}, \eta_{0}\right)$ of $T_{F}$ with the specified point of impact on the surface,

2. compute step by step the nodes of $\mathrm{T}_{\mathrm{F}}^{\Sigma}$, classified as $\alpha$-nodes, from the point of impact, associated with nodes $\left(\xi, \eta_{0}\right)$ of $\mathrm{T}_{\mathrm{F}}$,

3. compute step by step the nodes of $\mathrm{T}_{\mathrm{F}}^{\Sigma}$, classified also as $\alpha$-nodes, from the point of impact, associated with nodes $\left(\xi_{0}, \eta\right)$ of $\mathrm{T}_{\mathrm{F}}$,

4. compute cell by cell all the other nodes of $\mathrm{T}_{\mathrm{F}}^{\Sigma}$, classified as $\beta$ - nodes, from $x_{0}$ and the nodes associated with nodes $\left(\xi, \eta_{0}\right)$ and $\left(\xi_{0}, \eta\right)$ of $\mathrm{T}_{\mathrm{F}}$.

The nodes of $\mathrm{T}_{\mathrm{F}}^{\Sigma}$ associated with nodes $\left(\xi, \eta_{0}\right)$ and $\left(\xi_{0}, \eta\right)$ of $\mathrm{T}_{\mathrm{F}}$ (the $\alpha$ nodes) are putted on the surface along the geodesic lines emanating from the point of impact. Regarding the $\beta$ - nodes, various algorithms are proposed (Bergsma et al., 1988 ) and (Van Der Ween, 1999). Most of them use an analytical expression of the surface and formulate the draping problem in terms of non-linear partial differential equations. Other algorithms are also proposed to simplify these equations by using a discrete approximation of the surface by flat triangular face (i.e. a mesh of the surface).

Based on this latter approach we propose a new algorithm. The geodesic lines on the surface are approximated by the polylines plotted on the surface using linear orthogonal transformation in $\mathfrak{R}^{3}$ to setting flat the surface locally (these polylines become a straight line segment after these transformations). This allows us to determine the $\alpha$-nodes. Let $\mathrm{P}$ be an $\alpha$-node of $\mathrm{T}_{\mathrm{F}}^{\Sigma}$, and $\mathrm{K}$ be the element of $\mathrm{T}_{\Sigma}$ containing $\mathrm{P}$. To determine the geodesic line from $\mathrm{P}$ in a direction $\overrightarrow{\mathrm{u}}$, we compute the projection $\overrightarrow{\mathrm{u}}_{\mathrm{K}}$ of $\overrightarrow{\mathrm{u}}$ on element $\mathrm{K}$ and we proceed as follow:

- go through $\mathrm{K}$ in the direction $\overrightarrow{\mathrm{u}}_{\mathrm{K}}$ : we determine element $\mathrm{K}^{\prime}$ adjacent to $K$ intersecting direction $\overrightarrow{\mathrm{u}}_{\mathrm{K}}$,

- go from $K$ to $K^{\prime}$ : we compute the new direction $\vec{u}_{K^{\prime}}$ following $\vec{u}_{K}$ such that 
the angles of directions $\overrightarrow{\mathrm{u}}_{\mathrm{K}}$ and $\overrightarrow{\mathrm{u}}_{\mathrm{K}^{\prime}}$ with the common edge of $\mathrm{K}$ and $\mathrm{K}^{\prime}$ are the same (cf. Figure 2),

- replace $\mathrm{K}$ by $\mathrm{K}^{\prime}$, $\overrightarrow{\mathrm{u}}_{\mathrm{K}}$ by $\overrightarrow{\mathrm{u}}_{\mathrm{K}^{\prime}}$ and iterate.

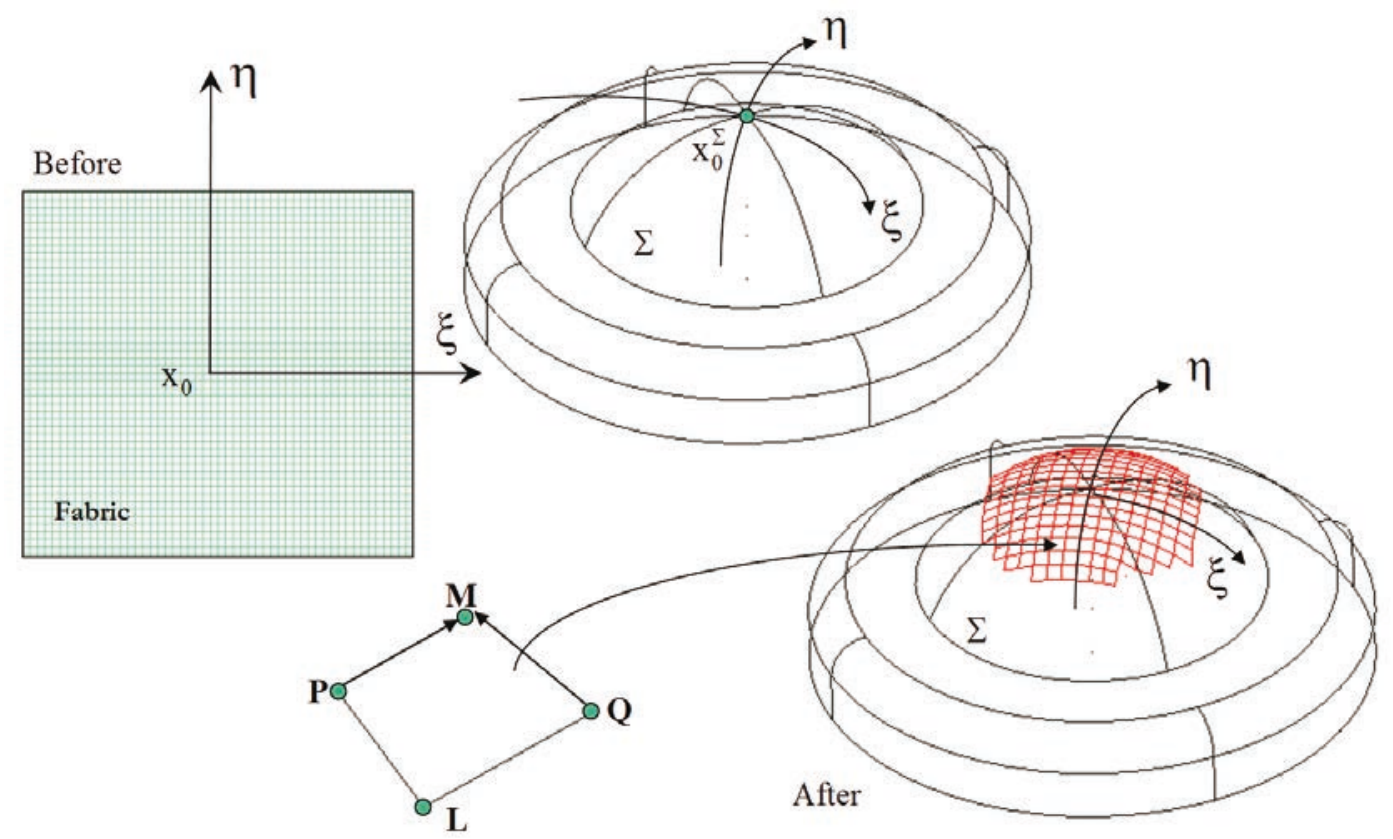

Figure 1. Geometrical draping of pre-preg woven fabric

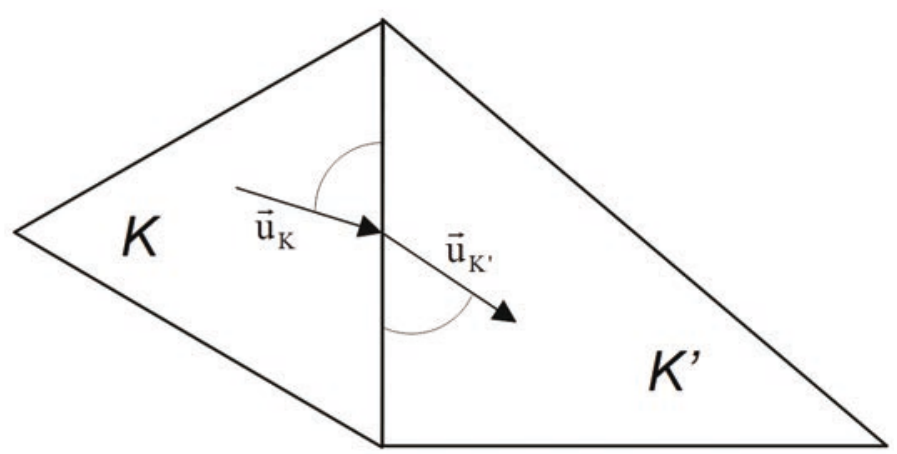

Figure 2. Computing Geodesic lines

The $\beta$-nodes are computed by solving an optimisation problem corresponding to determine a vertex of an equilateral quad plotted on the surface from the data of the three other vertices. This optimisation problem formulates the direction of the geodesic lines emanating from the searched vertex. Suppose that the specified length of the edges of mesh $\mathrm{T}_{\mathrm{F}}$ is 1 . Let $\mathrm{P}$ and $\mathrm{Q}$ be two nodes of $\mathrm{T}_{\mathrm{F}}^{\Sigma}$. To determine the geodesic segments emanating from $\mathrm{P}$ and $\mathrm{Q}$, intersecting mutually with a length 1 , the following algorithm is applied iteratively (directions $\overrightarrow{\mathrm{u}}$ and $\overrightarrow{\mathrm{v}}$ are appropriately initialized to obtain the desired solution between two possible solutions): 
- compute the extremity $\mathrm{P}^{\prime}$ of the geodesic segment of length 1 emanating from $\mathrm{P}$ in direction $\overrightarrow{\mathrm{u}}$,

- compute the extremity $\mathrm{Q}^{\prime}$ of the geodesic segment of length 1 emanating from Q in direction $\vec{v}$,

- if $\mathrm{P}^{\prime}$ is different from $\mathrm{Q}^{\prime}$, change $\overrightarrow{\mathrm{u}}$ and $\overrightarrow{\mathrm{v}}$ towards the mid point of segment $\mathrm{P}^{\prime} \mathrm{Q}^{\prime}$ and iterate (cf. Figure 3).
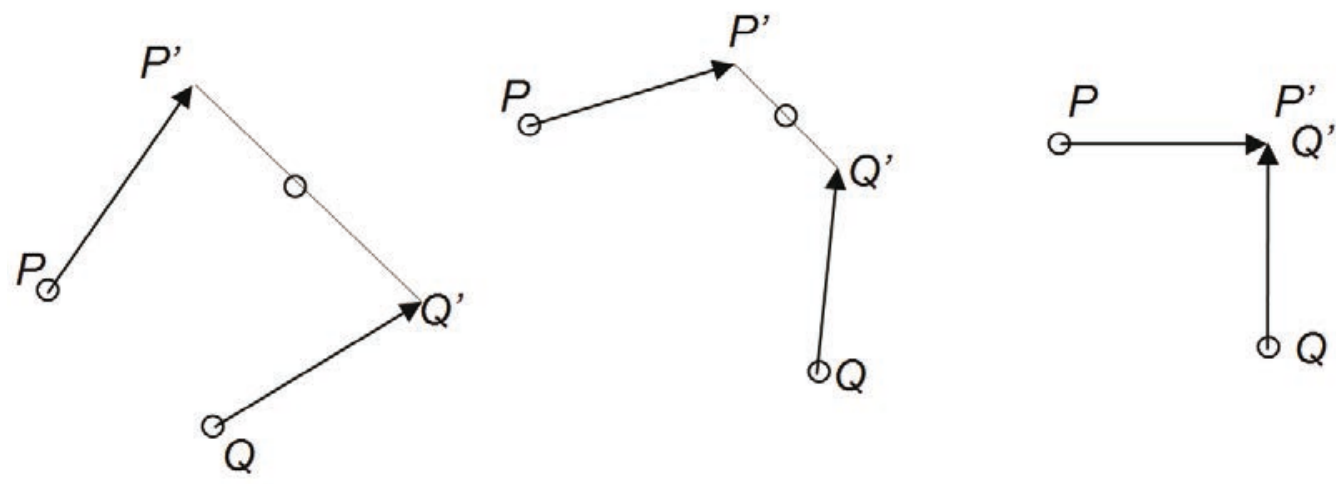

Figure 3. Computing $\beta$-nodes

Nodes of $\mathrm{T}_{\mathrm{F}}^{\Sigma}$ associated with nodes $(\xi, \eta)$ where $\xi \neq \xi_{0}$ and $\eta \neq \eta_{0}$ complete the mesh elements for which three nodes associated to $\left(\xi^{-}, \eta^{-}\right),\left(\xi^{-}, \eta\right)$ and $\left(\xi, \eta^{-}\right)$ are already placed on the surface mesh $\mathrm{T}_{\Sigma}$ (node of $\mathrm{T}_{\mathrm{F}}^{\Sigma}$ associated with $\left(\xi^{-}, \eta\right.$ ) (resp. $\left.\left(\xi, \eta^{-}\right)\right)$represents the node which precedes the node associated with $(\xi, \eta)$ in direction $\xi$ (resp. $\eta$ ) and node of $\mathrm{T}_{\mathrm{F}}^{\Sigma}$ associated with $\left(\xi^{-}, \eta^{-}\right)$is the node which precedes the node associated with $(\xi, \eta)$ in the two directions $\xi$ and $\eta)$. In the case where the mesh element touches the surface boundary, one of the nodes associated with nodes $\left(\xi^{-}, \eta\right)$ and $\left(\xi, \eta^{-}\right)$can be undefined and the proposed algorithm to determine node associated with $(\xi, \eta)$ can not be applied. In this case, we identify the node of $\mathrm{T}_{\mathrm{F}}^{\Sigma}$ associated with one of the node $\left(\xi^{-}, \eta\right)$ or $\left(\xi, \eta^{-}\right)$which is well defined (i.e. placed on the surface mesh) and we determine the node associated with $(\xi, \eta)$ on the geodesic line emanating from the well defined node associated with $\left(\xi^{-}, \eta\right)$ or $\left(\xi, \eta^{-}\right)$in direction $\xi$ or $\eta$. Let us suppose that the node associated with $\left(\xi^{-}, \eta\right)$ is well defined and that the node associated with $\left(\xi, \eta^{-}\right)$couldn't be placed on the surface mesh. Node associated with $(\xi, \eta)$ is then placed on the geodesic line emanating from node associated with $\left(\xi^{-}, \eta\right)$ in direction $\overrightarrow{\xi^{--} \xi^{-}}$where $\xi^{--}$is such that node associated with $\left(\xi^{--}, \eta\right)$ precedes node associated with $\left(\xi^{-}, \eta\right)$ in direction $\xi$ (cf. Figure 4). 


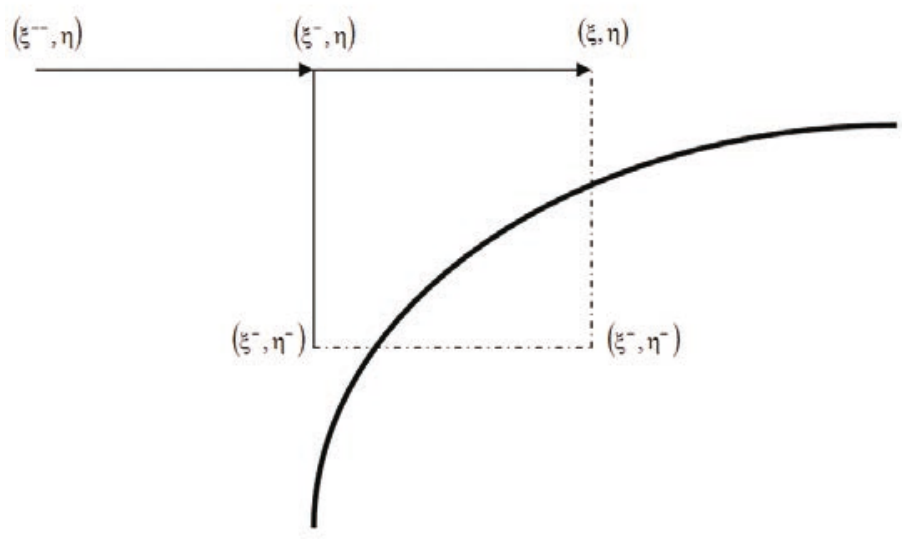

Figure 4. Computing boundary $\beta$-nodes

\section{Continuum mechanical approach}

The deformation modes of prepreg woven fabrics during the forming process are different than the classical continuous sheet metal (Cherouat et al., 1994), (Boisse, 2004) and (Liu et al., 2005). A number of mechanisms are available including shear deformation between warp and weft yarns, yarn straightening, relative slip deformation and yarn buckling. In the deep-drawing and the draping processes of prepreg woven fabrics, the evolution of two straight line grille draw alternatively on warp and weft yarns, shows that the fabric can be considered as a continuous 3D surface domain. During the deformation, the draw lines become curved but remain continuous (see Figure 5). The absence of inter-yarn sliding (ensured by the weaving fabric, the friction fiber/fiber and the friction fiber/resin) can be observed over the main areas of the fabric (i.e. far enough from the free edges of the fabric). The buckling mechanism will appear when certain zones are locally subjected to compressive forces along yarns axis. For the prepreg fabrics based on high modulus yarns, the compressive as well as bending stiffness are negligible compared to the in-plane membrane stiffness. The function of reinforcement is to cover complex shapes by angular variations between warp and weft fibers without excessive extension of yarns. The function of resin is to avoid inter-fiber sliding and transmit the effort to fibers by shearing strain. The consequence is that the shearing strain energy is small for dry woven fabric but not for prepreg woven fabric.
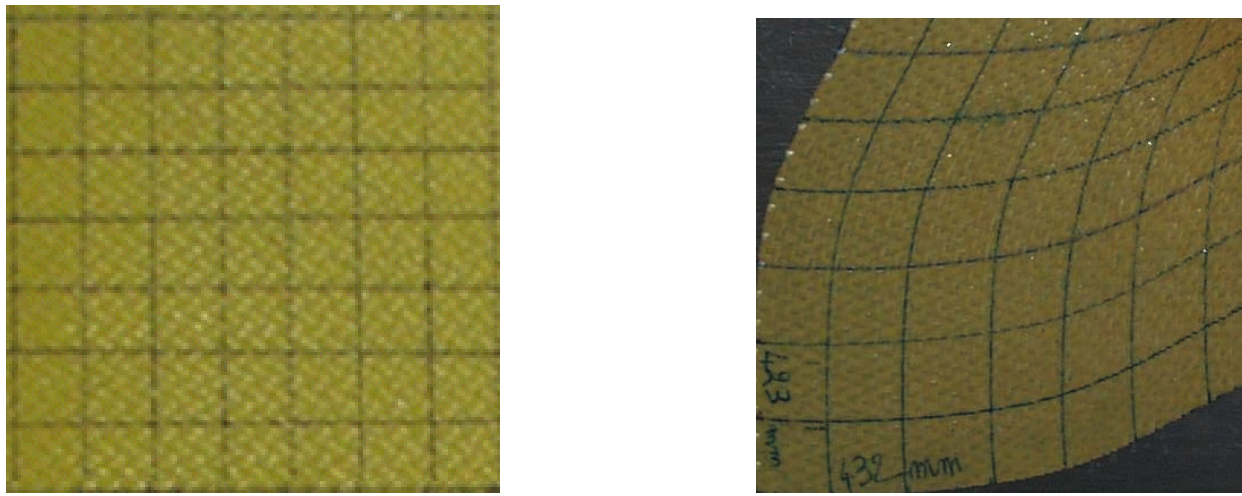

Figure 5. Deformation of woven fabric: straight lines before and after deformation 
The warp and weft yarns are assimilated as a truss which connecting points are hinged and the resin, considered as a membrane, is coupled kinematically to the prepreg fabric at these connecting points. For each connecting point $\overrightarrow{\mathrm{X}}^{\mathrm{f}}$ of warp and weft yarns, in the reference configuration $\mathrm{C}_{0}$, is associated a material position space of a resin $\vec{X}^{m}$ (see Figure 6). At the connecting points (I,J,K,L) we have $\overrightarrow{\mathrm{X}}^{\mathrm{f}}=\overrightarrow{\mathrm{X}}^{\mathrm{m}}=\overrightarrow{\mathrm{X}}$ before deformation. The current space position of these points after deformation $(\mathrm{i}, \mathrm{j}, \mathrm{k}, \mathrm{l})$ is obtained by

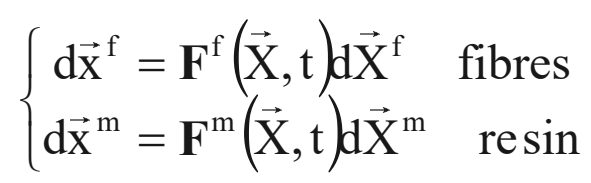

where $\mathbf{F}^{\mathrm{f}}$ and $\mathbf{F}^{\mathrm{m}}$ are the deformation gradient tensor of fibre and resin respectively. The relationship of the no sliding inter-fibre can write at each connecting point as $\vec{x}=\vec{x}(\vec{X}, t)$ with $x^{f}=x^{m}=x$. For these points we have $\mathbf{F}^{\mathrm{f}}=\mathbf{F}^{\mathrm{m}}$ but for all other point $\mathbf{F}^{\mathrm{f}} \neq \mathbf{F}^{\mathrm{m}}$. It is possible to decompose the deformation gradient tensor in terms of the rigid rotation tensor followed by a stretch. By the spectral theorem, the stretch component (scalar for the fiber $\lambda_{\mathrm{L}}^{\mathrm{f}}$ and tensor for the resin $\mathbf{U}^{\mathrm{m}}$ ) is defined in the reference configuration $\mathrm{C}_{0}$ as :

$$
\begin{cases}\lambda_{\mathrm{L}}^{\mathrm{f}}=\sqrt{\mathrm{N}_{\mathrm{L}}^{\mathrm{f}} \mathbf{F}^{\mathrm{f}^{\mathrm{T}}} \mathbf{F}^{\mathrm{f}} \mathrm{N}_{\mathrm{L}}^{\mathrm{f}}} & \text { fibres } \\ \mathbf{U}^{\mathrm{m}}=\sqrt{\mathbf{F}^{\mathrm{m}^{\mathrm{T}}} \mathbf{F}^{\mathrm{m}}} & \text { resin }\end{cases}
$$

Using the above assumptions, the mechanical behaviour of prepreg woven fabric depends on the deformation of yarns and the deformation of resin. The problem of the integration of strain rate tensors is a central one in large deformations. The rate equations for finite strains use objective derivatives (Gilormini et al., 1993). The frame associated with Green-Naghdi's derivative is defined, at the material point considered, by the rigid body rotation of the triplet orthogonal material directions $\left(\mathrm{N}_{\mathrm{i}}^{\mathrm{f}} \otimes \mathrm{N}_{\mathrm{i}}^{\mathrm{f}}\right.$ for the fibre and $\mathrm{e}_{0 \mathrm{i}} \otimes \mathrm{e}_{0 \mathrm{i}}$ for the resin). The stretching tensors are written in the material frames.

$$
\begin{cases}\overline{\mathbf{D}}_{\mathrm{L}}^{\mathrm{f}}=\left(\frac{\lambda_{\mathrm{L}}^{\mathrm{f}}}{\lambda_{\mathrm{L}}^{\mathrm{f}}}\right)\left(\mathrm{N}_{\mathrm{L}}^{\mathrm{f}} \otimes \mathrm{N}_{\mathrm{L}}^{\mathrm{f}}\right) & \text { fibres } \\ \overline{\mathbf{D}}^{\mathrm{m}}=\mathbf{U}^{\mathrm{m}} \mathbf{U}^{\mathrm{m}^{-1}}\left(\mathrm{e}_{0 \mathrm{i}} \otimes \mathrm{e}_{0 \mathrm{i}}\right) & \text { re sin }\end{cases}
$$

The longitudinal fibres stress $\bar{\sigma}_{\mathrm{L}}^{\mathrm{f}}$, depending on the fibre stretching elongation $\overline{\mathrm{D}}_{\mathrm{L}}^{\mathrm{f}}$, and the resin membrane stress tensor $\bar{\sigma}^{\mathrm{m}}$ can be written at each time as: 


$$
\begin{cases}\dot{\bar{\sigma}}_{\mathrm{L}}^{\mathrm{f}}=\mathrm{E}_{\mathrm{L}}^{\mathrm{f}}\left(\lambda_{\mathrm{L}}^{\mathrm{f}}\right) \overline{\mathrm{D}}_{\mathrm{L}}^{\mathrm{f}} & \text { fibres } \\ \dot{\bar{\sigma}}^{\mathrm{m}}=\mathbf{C}^{\mathrm{m}}(\tau) \cdot \overline{\mathbf{D}}^{\mathrm{m}} & \text { resin }\end{cases}
$$

Because of the weaving, the behaviour in tension of the fibres is elastic nonlinear and is related to elastic modulus $\overline{\mathrm{E}}_{\mathrm{f}}$ and yarns undulation factor $\varepsilon_{\mathrm{sh}}$. In compression, the behaviour of fibres is supposed negligible. The viscoelastic behaviour of resin is formulates in the time domain by the hereditary integral and using the relaxation time $\tau_{\mathrm{k}}$ and the fourth order relaxation tensor, which are material parameters $\mathrm{C}_{\mathrm{ij}}^{\mathrm{m}^{\mathrm{k}}}$ :

$$
\left\{\begin{array}{cc}
E_{L}^{f}\left(\lambda_{L}^{f}\right)=\bar{E}_{f}\left(1+\exp \left(\frac{-\dot{\lambda}_{L}^{f}}{\lambda_{L}^{f} \varepsilon_{s h}}\right)\right. & \text { fibres } \\
C_{i j}^{m}(t)=C_{i j}^{m^{\infty}}+\sum_{1}^{k} C_{i j}^{m^{k}} e^{-t / \tau_{k}} & \text { re sin }
\end{array}\right.
$$

The governing equilibrium equations are solved as a dynamic problem using explicit integration. This approach has proven to be, in particular, suitable to highly non-linear geometric and material problems, particularly where a large amount of contact between different structural parts occurs. The analyses are carried out using the FEA computer code Abaqus/Explicit (Abaqus, 2002). The detailed formulations are described elsewhere (Cherouat et al., 1999).

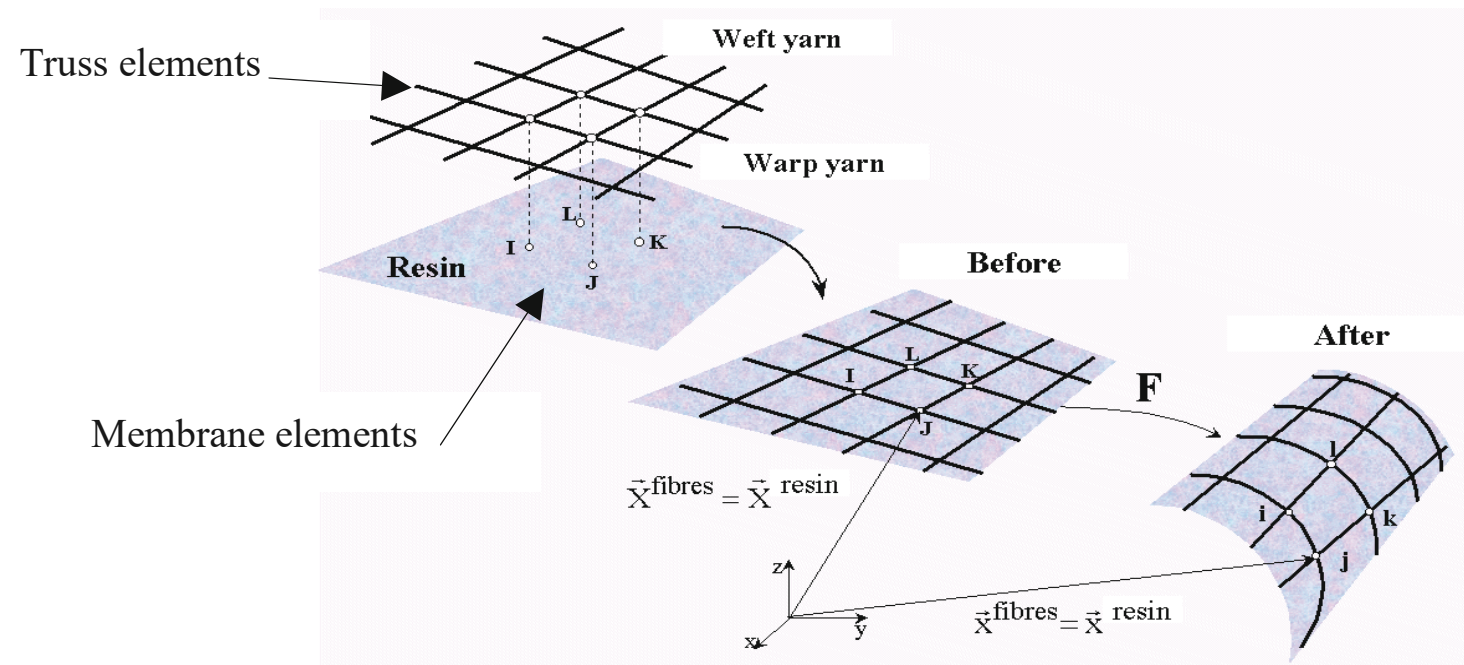

Figure 6. Mechanical deformation of prepreg woven fabric

\section{Numerical examples}

Four draping simulation examples are given. These simulations are performed using the geometrical analysis computer code GeomDrap (Borouchaki et al., 1999) and the FEA computer code Abaqus/explicit. For each example, we assume that a 
mesh of the piece to drape is given. The first and fourth examples show the influence of the fibre orientations draping in the draping process. The first one uses the pure geometrical approach while the fourth concerns both the mechanical approach and experimental results. The last example concerns the 3D deep-drawing of complex part using mechanical approach and experimental results.

The first example concerns the discrete geometrical draping of a base plate piece. The centroid of this piece is chosen as the point of impact for which two different fibre orientations: $\left(0^{\circ} / 90^{\circ}\right)$ and $\left(-45^{\circ} / 45^{\circ}\right)$ are specified. Figure 7 shows the resulting $3 \mathrm{D}$ surface lay-up for the $\left(0^{\circ} / 90^{\circ}\right)$ fibre orientation and the $2 \mathrm{D}$ corresponding flat patterns. Likewise, Figure 8 shows the draping results for the $\left(-45^{\circ} / 45^{\circ}\right)$ fibre orientation. One can notice that, in the considered cases, the surface of the piece is draped globally. However, in the second case, a smaller area of the flat fabric is used. This result shows the importance of the fabric orientation in the draping process.

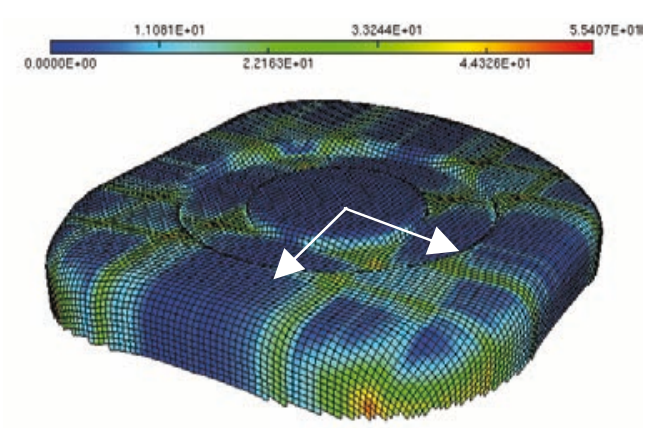

(a) $\left(0^{\circ} / 90^{\circ}\right)$

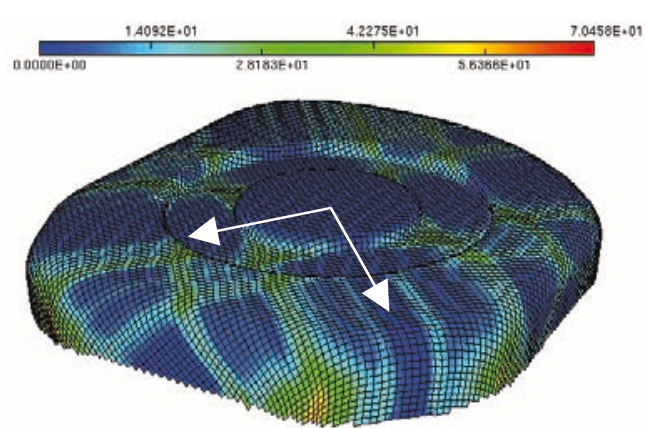

(b) $\left(-45^{\circ} / 45^{\circ}\right)$

Figure 7. Geometrical draping of mechanical piece

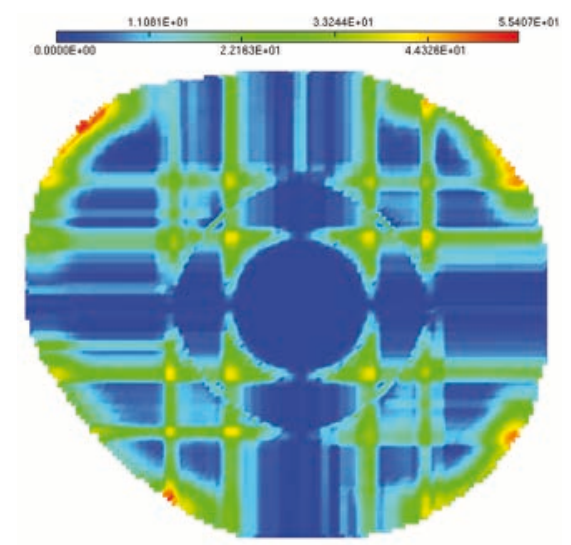

(a) $\left(0^{\circ} / 90^{\circ}\right)$

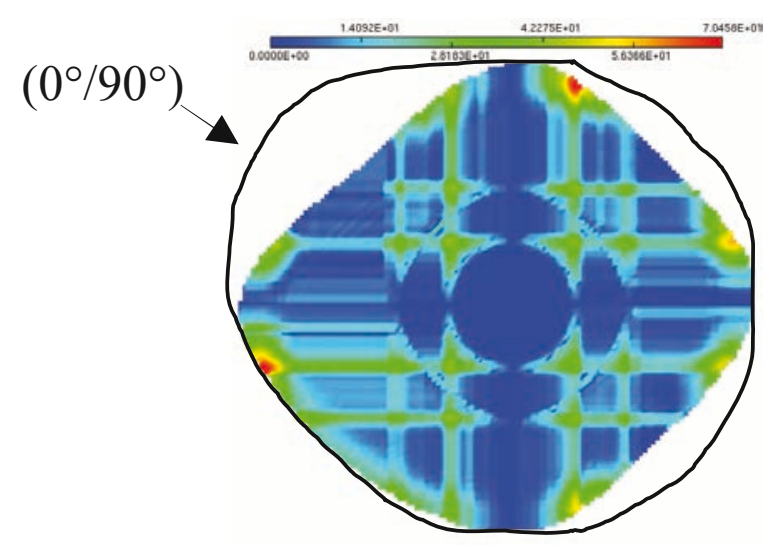

(b) $\left(-45^{\circ} / 45^{\circ}\right)$

Figure 8. 2D Flat patterns of the composite parts

The second example is also a discrete geometrical draping. The considered part is a car hood. The centroid of the part is chosen as the point of impact from which the $\left(0^{\circ} / 90^{\circ}\right)$ and $\left(-45^{\circ} / 45^{\circ}\right)$ fibre orientations are specified. Figure 9 shows the 
resulting 3D draping without applying the particular procedure for boundary $\beta$-node. We can note that the surface part is not totally covered. Figure 10 shows the 3D draping of the part using the boundary $\beta$-node treatment. All of the surface part is now draped. Figure 11 presents shaded contours interpolated from the map of the fiber distorsions of $\left(0^{\circ} / 90^{\circ}\right)$ and $\left(-45^{\circ} / 45^{\circ}\right)$ fiber orientations. The fiber distorsions for both $\left(0^{\circ} / 90^{\circ}\right)$ and $\left(-45^{\circ} / 45^{\circ}\right)$ draping are very small.
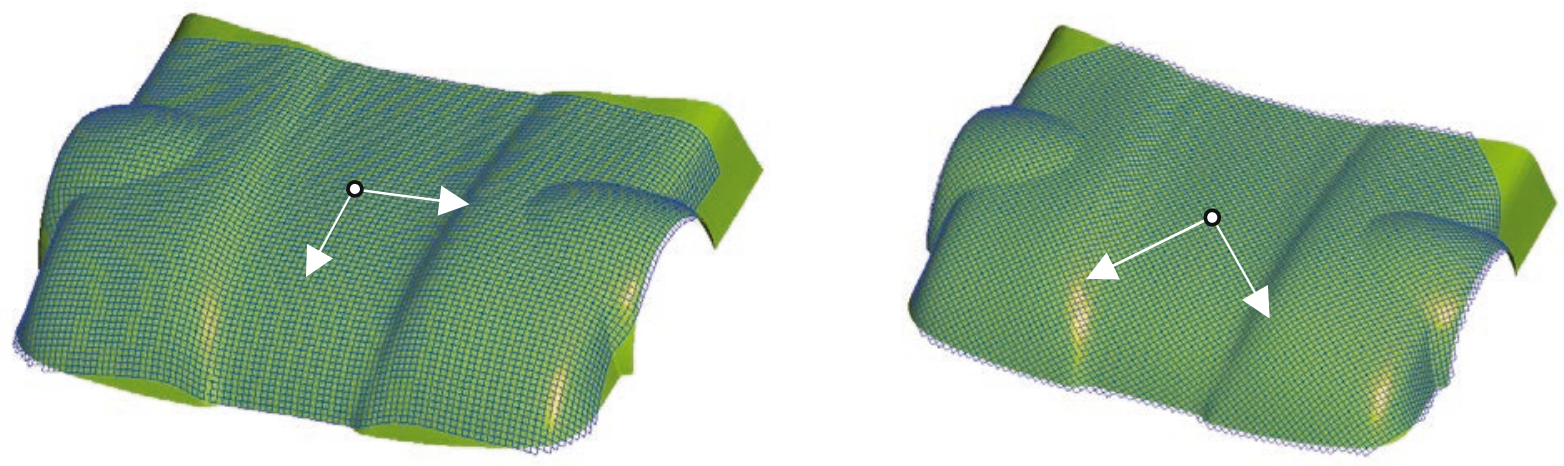

Figure 9. Geometrical draping at $\left(0^{\circ} / 90^{\circ}\right)$ and $\left(-45^{\circ} / 45^{\circ}\right)$
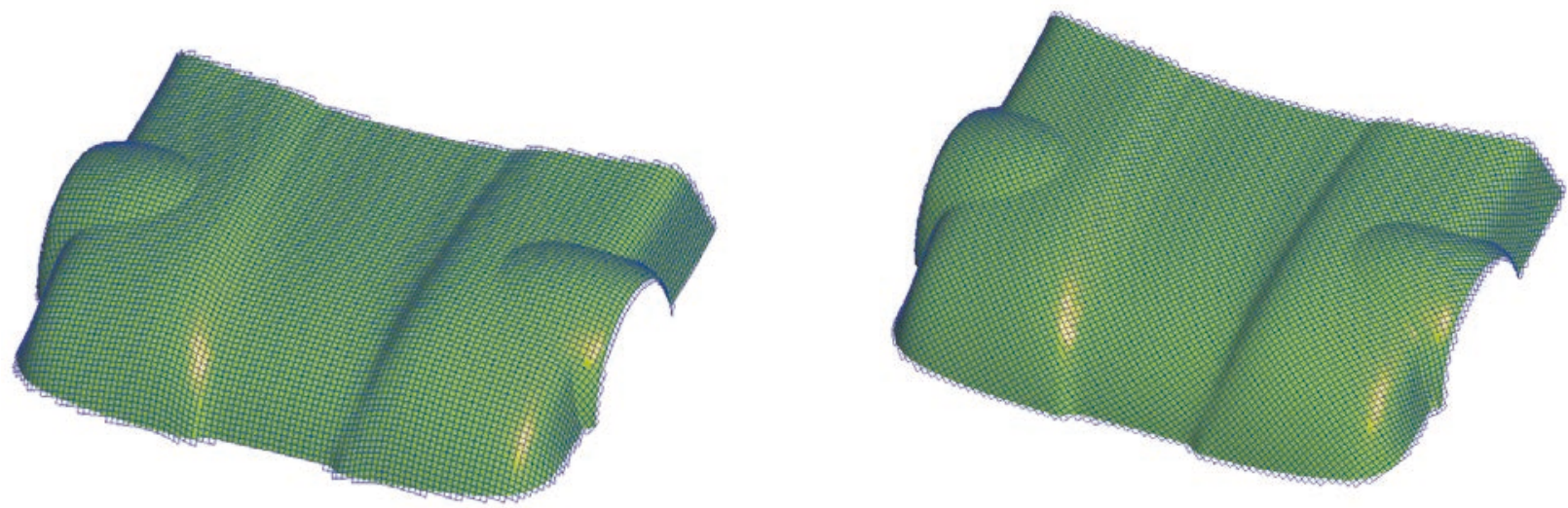

Figure 10. Geometrical whole draping at $\left(0^{\circ} / 90^{\circ}\right)$ and $\left(-45^{\circ} / 45^{\circ}\right)$
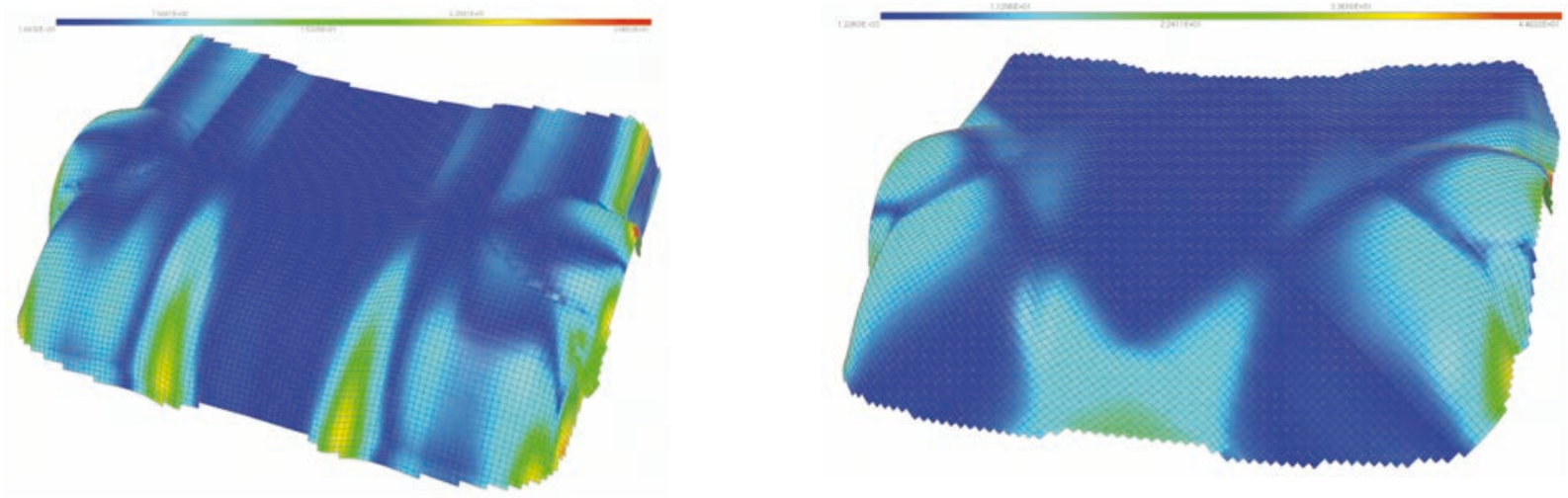

Figure 11. Fibre distorsions map at $\left(0^{\circ} / 90^{\circ}\right)$ and $\left(-45^{\circ} / 45^{\circ}\right)$ 
The third example is the mechanical draping of a prepreg fabric (carbon fibre) on a hemispherical shape. The resin is modelled with linear membrane finite elements (triangular 3 nodes M3D3 and quadrilateral 4 nodes M3D4 of Abaqus elements), the warp and weft fibres are initially modelled with two orthogonal linear truss finite elements (T2D2) and the hemisphere tool is modelled by rigid surfaces (triangular 3 nodes R3D3 and quadrilateral 4 nodes R3D4). The behaviour of the resin is isotropic viscoelastic and the behavior of the fibres is elastic non-linear. As for the first example, we consider the two fibre orientations $\left(0^{\circ} / 90^{\circ}\right)$ and $\left(-45^{\circ} / 45^{\circ}\right)$. Figure 12 shows the experimental draping with respect to these orientations. Notice that the initial directions of the fibre influence the final resulting shape. Figure 13 illustrates the numerical final shapes (for each orientation) obtained by mechanical approach. The numerical results are in good agreement with the experimental one.
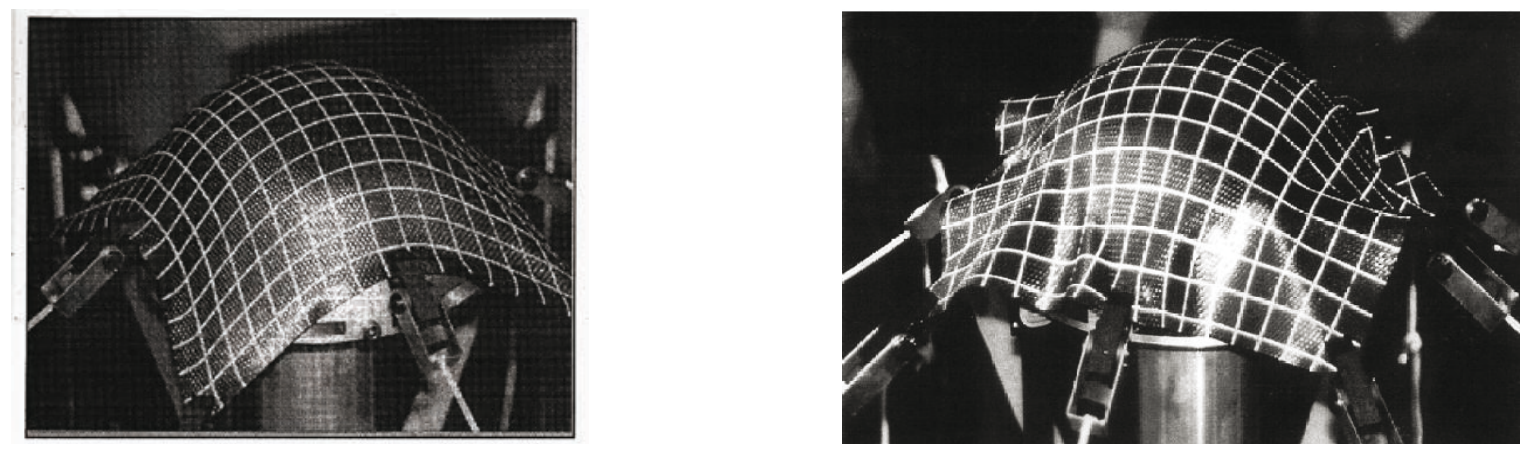

Figure 12. Experimental draping at $\left(0^{\circ} / 90^{\circ}\right)$ and $\left(-45^{\circ} / 45^{\circ}\right)$
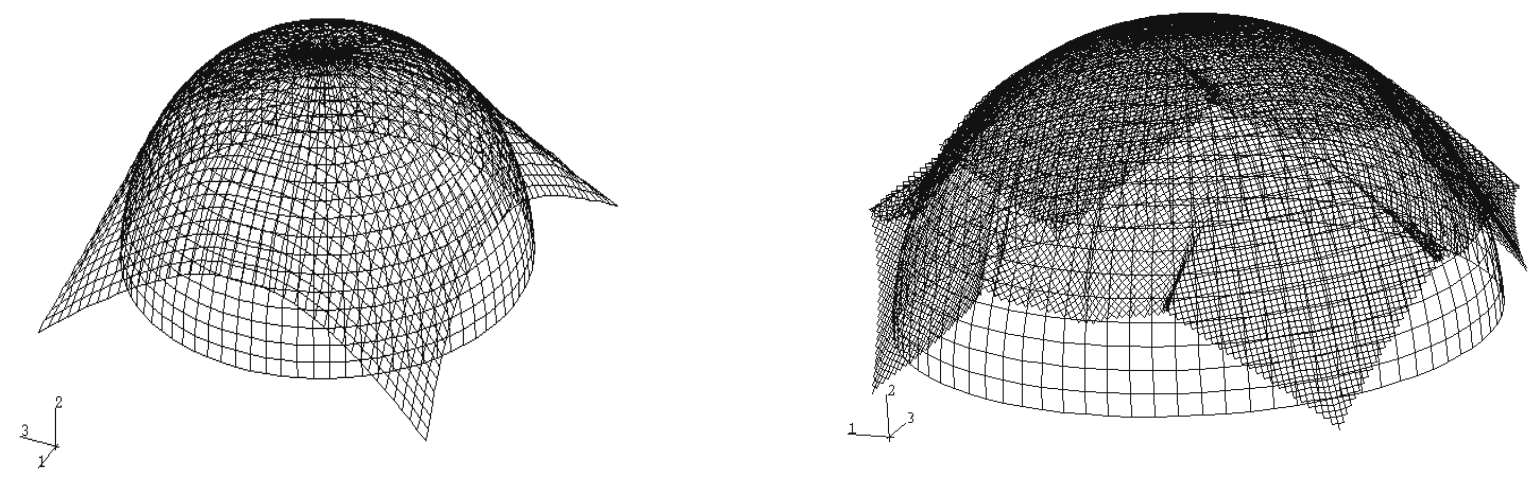

Figure 13. Numerical draping at $\left(0^{\circ} / 90^{\circ}\right)$ and $\left(-45^{\circ} / 45^{\circ}\right)$

The last example shows the 3D deep-drawing of aramid prepreg fabric with conical tools. Figures 14a, 14b, 14c and 14d report the experimental obtained shapes with respect to $\left(-45^{\circ} / 45^{\circ}\right)$ fibre orientation for different punch displacements $(\mathrm{u}=0 \mathrm{~mm}, 20,60$ and $100 \mathrm{~mm}$, respectively). Figures $14 \mathrm{e}$ and $14 \mathrm{f}$ show the experimental shapes with respect to $\left(0^{\circ} / 90^{\circ}\right)$ and $\left(-45^{\circ} / 45^{\circ}\right)$ fiber orientations at 100 $\mathrm{mm}$ of punch displacement. Notice that, the initial directions of the fiber influence considerably the final resulting shape. Figure 15 presents shaded contours interpolated from the map of the fiber distorsions of $\left(0^{\circ} / 90^{\circ}\right)$ and $\left(-45^{\circ} / 45^{\circ}\right)$ fiber 
orientations. The fiber distorsion is represented by the orientation of the deformed truss elements (warp and weft). The angular fibre distortion exceeds $38^{\circ}$ along the diagonal axis for $\left(0^{\circ} / 90^{\circ}\right)$ fibre orientations (Figure 16a) and along the diagonal axis for $\left(-45^{\circ} / 45^{\circ}\right)$ fibre orientations (Figure 16b).

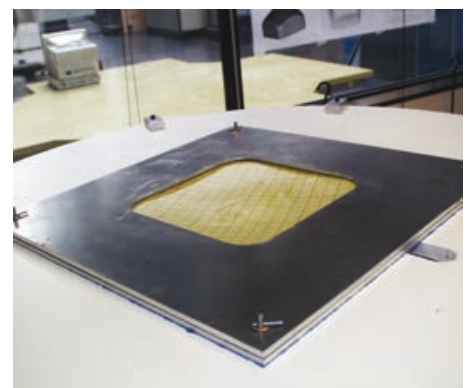

(a) initial configuration

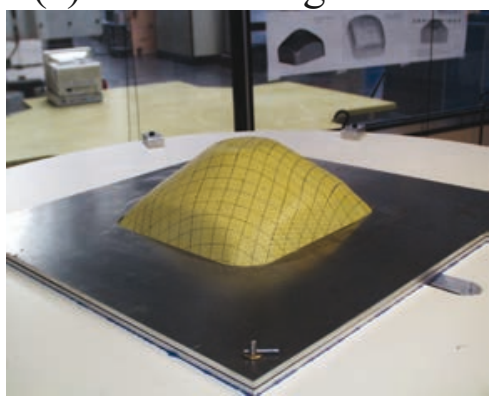

(c) $\mathrm{u}=60 \mathrm{~mm}$

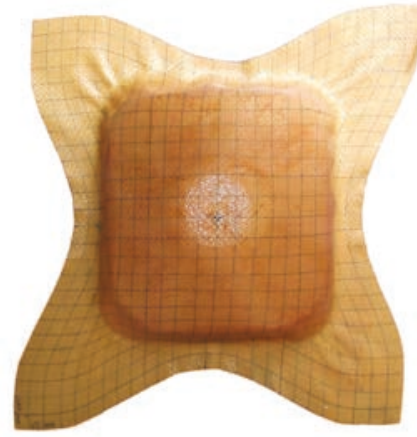

(e) $\left(0^{\circ} / 90^{\circ}\right)$

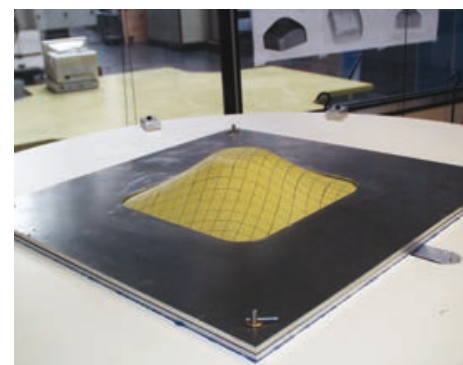

(b) $\mathrm{u}=20 \mathrm{~mm}$

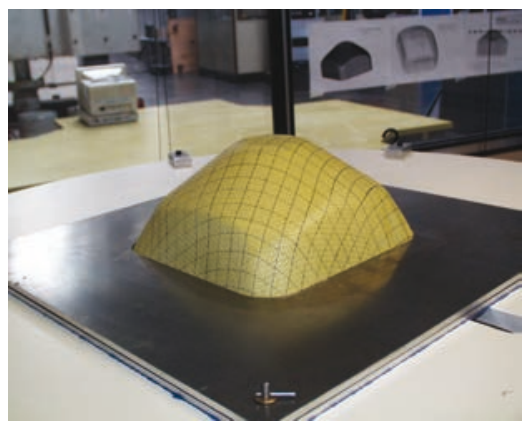

(d) $\mathrm{u}=100 \mathrm{~mm}$

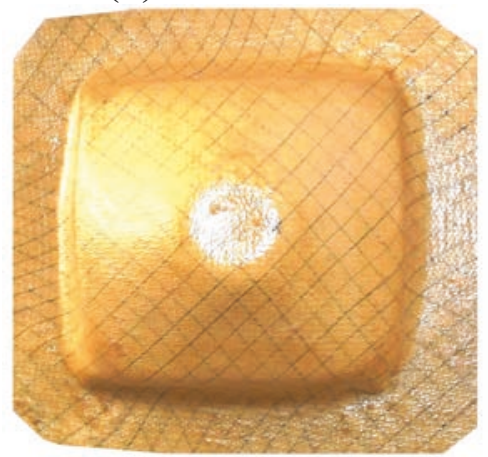

(f) $\left(-45^{\circ} / 45^{\circ}\right)$

Figure 14. Experimental deep-drawing at $\left(0^{\circ} / 90^{\circ}\right)$ and $\left(-45^{\circ} / 45^{\circ}\right)$

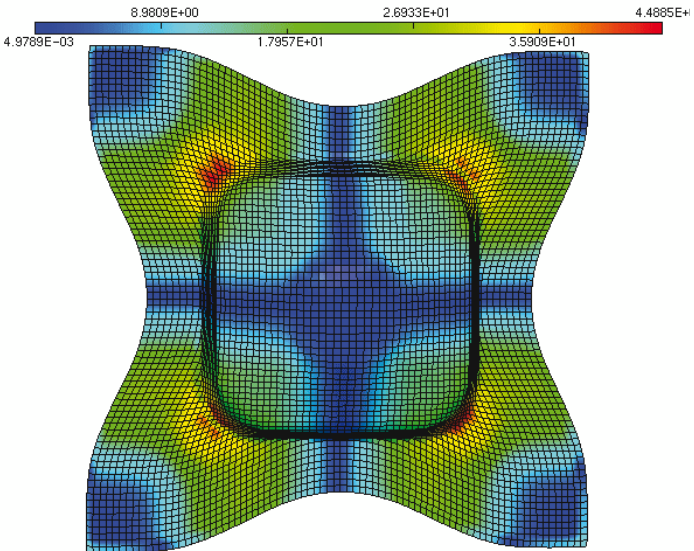

(a) $\left(0^{\circ} / 90^{\circ}\right)$

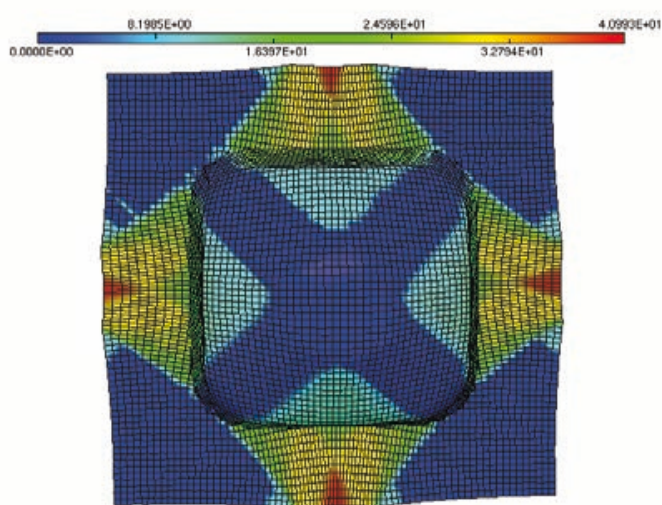

(b) $\left(-45^{\circ} / 45^{\circ}\right)$

Figure 15. Fibre distorsions map for $100 \mathrm{~mm}$ of punch displacement 

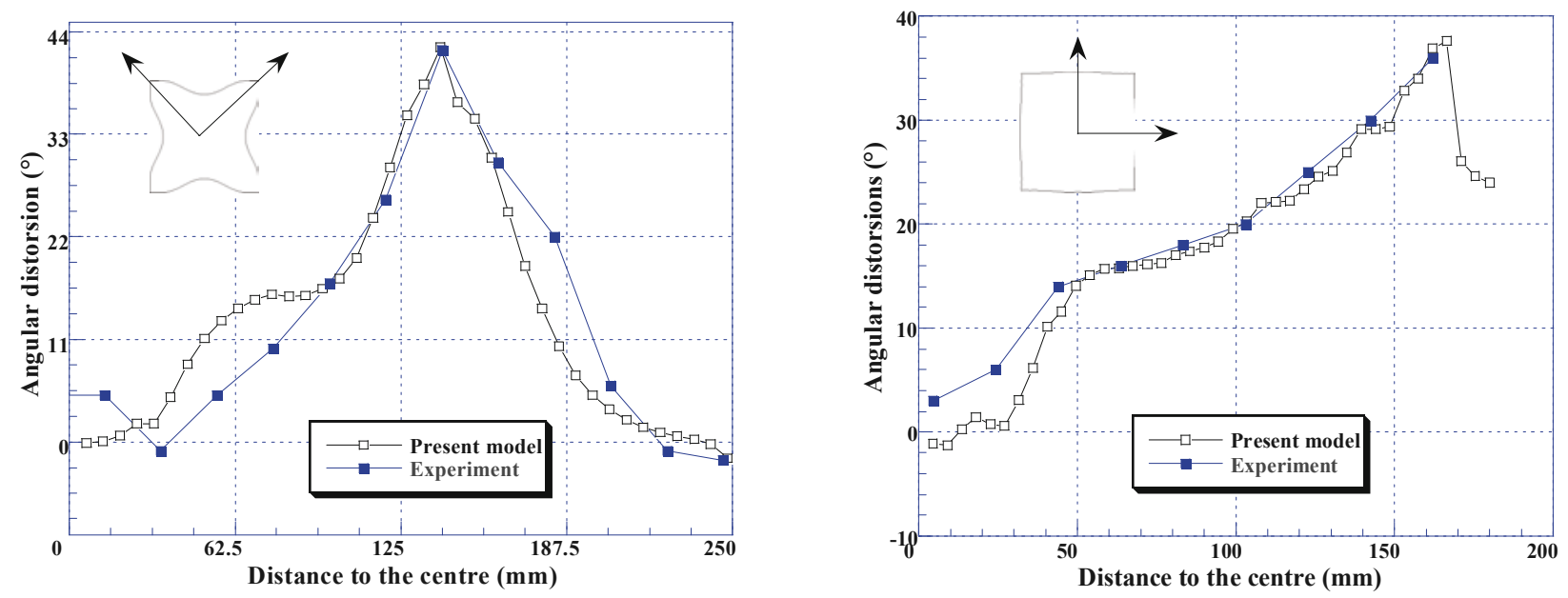

Figure 16. Angular distorsions along the fabric lines (a) $0 \% 90^{\circ}$ and (b) $\left(-45^{\circ} / 45^{\circ}\right)$

\section{Conclusions}

An efficient numerical approach (geometrical and mechanical) has been presented to simulate accurately the draping of composite fabric. This numerical methodology is shown to be very helpful for composite forming process.

\section{References}

Abaqus theory, User's Manual, 2002.

Bergsma O.K., Huisman J., "Deep Drawing of fabric reinforced thermoplastic", $2^{\text {nd }}$ Inter. Conf. Comp. Aided Design in Composite Material Technology, 1988, pp. 323-333.

Binétruy C., "Physique du moulage des composites avancés: aspects théoriques", Techniques de l'ingénieur, AM 3718, 2004, pp. 1-16.

Boisse P., "Mise en forme des renforts fibreux de composites ", Techniques de l'ingénieur, AM 3734, 2004, pp. 1-10.

Borouchaki H., Cherouat A., Billoët J.L., GeomDrap New Computer Aided Design and Manufacturing for Advanced Textile Composites, Version 1, 1999.

Borouchaki H., Cherouat A., "Drapage géométrique des composites", C.R. Acad. Sci. Paris,

Série II B, Mécanique des solides et des structures, Vol. 331, 2003, pp. 437-442.

Cherouat A., Gelin J.C., Boisse P., Sabhi H., "Modélisation de l'emboutissage des tissus de fibres de verre par la méthode des éléments finis", Revue Européenne des Eléments Finis, Vol. 4, 1995, pp. 159-182.

Cherouat A., Billoët J.L., "Mechanical and numerical modelling of composite manufacturing processes deep-drawing and laying-up of thin pre-impregnated woven fabrics", J. Mat. Proc. Technology, Vol. 118, 2001, pp. 460-471.

Gilormini P., Roudier P., Abaqus and Finite Strain, Rapport interne No. 140, 1993, Cachan. 
Harrison P., Clifford M.J., Long A.C., Rudd C.D., "A constituent-based predictive approach to modelling the rheology of viscous textile", Composites Part A, Vol. 35, 2004, pp. 915931.

Kawabata S., Niwa M., Kawai H., "The Finite deformation theory of plain-weave fabrics", J. Text. Inst, Parts I, II and III, Vol. 64, 1973, pp. 21-83.

Lim T.C., Ramakrishna S., Shang H.M., "Optimization of the formability of knitted fabric composite sheet by means of combined deep drawing and stretch forming", J. of Materials Processing Technology, Vol. 89-90, 1999, pp. 99-103.

Liu L., Chen J., Li X., Sherwood J., "Two-dimensional macro-mechanics shear models of woven fabrics", Composites Part A, Vol. 36, 2005, pp. 105-114.

Rozant O., Bourban P.E., Manson J.A.E., "Drapability of dry textile fabrics for stampable thermoplastic performs", Composites Part A, Vol. 31, 2000, pp. 1167-1177.

Van Der Ween F., "Algorithms for draping fabrics on doubly curved surfaces", Int. J. Num. Meth. Engng, 31, 1999, pp. 1415-1426. 